\title{
Ироническое начало в фельетоне Киев-город Михаила Булгакова
}

\section{Irony in Mikhail Bulgakov's feuilleton Kiev, the City}

\begin{abstract}
The subject of the article is the analysis of the image of Kiev, presented in Mikhail Bulgakov's feuilleton Kiev, the City. This work has rarely been the subject of in-depth analysis, despite the fact that it is one of the few texts in which the writer presents the image of his hometown. A characteristic element of the description of Kiev's past and present is the irony. It is noticeable in the title of the feuilleton, as well as in the names of its parts. The ironic image of Soviet Kiev stands in stark contrast to the vision of the city captured in the novel The White Guard. The analysis of the techniques used by the writer in the text of Kiev, the City (e.g. the naive narrator's mask, a combination of pompous style and colloquial speech) is carried out in order to prove that the feuilleton, in its style and ideas expressed, also shows the author's rejection of post-revolutionary reality and his attempt to overcome the trauma of the past through laughter. The ironic image of the Soviet reality on the background of eternal spiritual values makes Kiev, the City a harbinger of the problems covered in Mikhail Bulgakov's later works.
\end{abstract}

Keywords: Mikhail Bulgakov, Kiev, the city, irony, Bulgakov's early works, Kiev in literature

Antoni Bortnowski, Uniwersytet im. Adama Mickiewicza w Poznaniu, Poznań - Polska, a.bortnowski@amu.edu.pl, ORCID ID: https://orcid.org/0000-0002-9963-1798

Темой нашей статьи является ироническое начало в фельетоне Киев-город. Это небольшое по объему (10 страниц) и публицистическое по своей сути произведение относится к периоду работы Михаила Булгакова для сменовеховской газеты „Накануне”, в которой оно и было опубликовано 6 июля 1923 года. Киев-город, так же как и большинство других публицистических текстов Булгакова, до сих пор не дождался подробного изучения, что особенно заметно на фоне интереса, вызываемого художественными произведениями автора и прежде всего, конечно, романом Мастер и Mаргарита. Публицистика Булгакова относительно мало изучена даже на фоне работ о раннем творчестве писателя. 
Монографии, посвященные собственно жизни и творчеству Михаила Булгакова и выходившие с 1980-х годов - Творческий путь Михаила Булгакова (1983) Лидии Яновской, Жизнеописание Михаила Булгакова (1988) Мариэтты Чудаковой, Вопросы изучения художественного наследия М.А. Булгакова (1999) Владимира Немцева, Мотивы прозы Михаила Булгакова (1997) и Текст и подтекст в рассказах М. Булгакова (2002) Евгения Яблокова, Жизнь Булгакова: дописать раньше, чем умереть (2001) Виктора Петелина, Проза Михаила Булгакова. Текст и метатекст (2002) Ольги Бердяевой, Михаил Булгаков (2008) Алексея Варламова и другие, - лишь констатируют фельетоны как факт творческой биографии художника или, как замечает Мария Кривошейкина, используют во многом автобиографичные накануньевские фельетоны-очерки для реконструкции того периода в жизни писателя, когда создавались Белая гвардия, Дьяволиада, Записки юного врача (Krivošejkina 3).

Киев-город в этом плане не является исключением. Целостный анализ данного произведения сегодня, по нашим сведениям, отсутствует, а если даже кто-то из исследователей на нем останавливается, то чаще всего он представляет лишь пересказ содержания, вроде лаконичного высказывания в книге Константина Трунина:

\footnotetext{
Через две недели [после фельетона Комаровское дело Булгаков - А.Б.] напишет воспоминания о Киеве 1917 года, где расскажет о горящем доме, вывесках на украинском языке и о Петлюре, не сумевшем ни в одной из четырех попыток взять город. Еще Булгаков выскажет утверждение про пристрастие москвичей к американскому, тогда как киевляне оным не обладают (Trunin, электронный ресурс).
}

Немного больше на тему данного фельетона можно прочитать в Булгаковской энщиклопедии Бориса Соколова, где, кроме пересказа содержания, отмечено, что в Киеве-городе „органически сочетается эпическое (при описании бурных и трагических событий революции и гражданской войны), лирическое (когда идут воспоминания о «беспечальном», юном поколении) и сатирическое (при характеристике современного состояния города)" (Sokolov, электронный ресурс).

Упомянем также статьи, посвященные сравнительному анализу очерка Киев-город: Мандельштам и Булгаков о городе Киеве. Опьт сопоставления (2013) Олега Оленева, Специфика гоголевского присутствия в тексте очер$\kappa a$,Киев-город” М.А. Булгакова (2016) Евгении Ивановой.

Такое положение вещей следует назвать неоправданным, так как данный фельетон, или очерк, как называют его некоторые ученые, занимает, по нашему мнению, особенное место в раннем творчестве Михаила Булгакова, являясь одним из немногочисленных текстов, затрагивающих столь важную для писателя киевскую тему. Как отметил в своей известной книге Мирон 
Петровский, „катастрофа, пережитая Булгаковым в Киеве в годы революции и Гражданской войны, была, по-видимому, самым серьезным событием в его жизни. [...] Киевская эсхатология Михаила Булгакова - «сокрытый двигатель его»" (Petrovskij 370-371).

Будущий автор Белой гвардии покинул Киев летом 1919 года, в разгар Гражданской войны, а в 1923 году посещает его вновь, по командировке от газеты „Накануне”. Можно предположить, насколько сложной задачей для Булгакова было не только вернуться в разоренный историческими потрясениями родной город, но еще и написать на основании своих наблюдений легкий и комический фельетон. Это обстоятельство, а также отношение автора к советской действительности, ярко выраженное в более поздних произведениях, являются, на наш взгляд, ключевыми для осмысления Киева-города в целом и раскрытия значения текстообразующей в случае данного фельетона иронии.

Ровно за год до публикации Киева-города в „Накануне”, в июле 1922 года, была открыта московская редакция газеты, задачей которой, как замечает Мария Кривошейкина, было ознакомление русского читателя в эмиграции с жизнью и бытом Советской России, с перспективами ее развития (Krivošejkina 7). В анализируемом нами фельетоне уже на этапе реализации этой основной, казалось бы, задачи текста заметен ироничный подход автора, который довольно хаотичным образом подбирает отдельные элементы киевской действительности начала 20 -х гг. (последствия гражданской войны, украинизация, значение Американской администрации помощи, жизнь киевских старушек, церковный раскол, памятник Карлу Марксу) и, представляя их в комическом ключе, не вникает в истинную природу явлений. Булгаков явно использует маску непрофессионального журналиста, который при всем желании не справляется ни с описанием и оценкой актуального положения вещей, ни тем более с представлением читателю перспектив развития советского Киева.

Название фельетона - Киев-город - на первый взгляд подчеркивает высокий статус метрополии, явно отсылая к известному из старорусских текстов определению „стольный Киев-град” (об истории возникновения формулы „стольный Киев-град” см. Vvedenskij). В действительности, как нам кажется, созвучность заглавия Булгакова с древнерусским определением иронично указывает на деградацию „матери городов русских”, которая утратила свой древний статус и перешла в разряд скорее провинциальных городов. Замена компонента „град” более современной формой „город” явно

\footnotetext{
1 „Мать городов русских” - очередное общеизвестное определение Киева, подчеркивающее значение города в качестве духовной колыбели восточного славянства.
} 
подчеркивает нелепость советских попыток изменить все на новый лад. Как снисходительно отмечено в самом тексте, „Киев такая тихая заводь теперь” (Bulgakov 98). Сравнение города с речным затоном, безусловно, можно рассматривать в ироническом ключе как намек на некую маргинализацию Киева, оказавшегося в тупике истории, вне главного ее русла.

Следует обратить внимание, что этот „диагноз”, поставленный в иронической форме родному городу, касается только советского Киева, который автор явно отделяет от вечного города-символа, хорошо известного из Белой гвардии. Это четко видно в обрамляющих Киев-город фрагментах, формирующих кольцевую композицию фельетона. Симптоматично, что начало и конец произведения, посвященные близкому автору вневременному городу и вызывающие определенные ассоциации с Белой гвардией, совершенно лишены иронии.

Весной зацветали белым цветом сады, одевался в зелень Царский сад, солнце ломилось во все окна, зажигало в них пожары. А Днепр! А закаты! А Выдубецкий монастырь на склонах! Зеленое море уступами сбегало к разноцветному ласковому Днепру. Черно-синие густые ночи над водой, электрический крест Св. Владимира, висящий в высоте... Словом, город прекрасный, город счастливый. Мать городов русских (Bulgakov 98).

Этот открывающий фельетон лирический фрагмент, своей тональностью перекликающийся с образами Города из Белой гвардии, ярко контрастирует с наполненной иронией основной частью текста. Автор в определенный момент резко обрывает свои полные восторга рассуждения, словно вспомнив об основной задаче фельетона - представить актуальное положение вещей в советском Киеве: „Легендарные времена оборвались, и внезапно, и грозно наступила история. Я совершенно точно могу указать момент ее появления: это было в 10 час. утра 2-го марта 1917 года" (Bulgakov 98).

Резкий переход от лирических размышлений к изложению истории гражданской войны в Киеве, дополнительно подчеркнутый канцелярской точностью сообщения, подчеркивает контраст между двумя частями текста и усиливает иронический эффект. Так же внезапно в последней главе, названной Финал, повествователь возвращается к рассуждениям, оборванным в начале текста:

Город прекрасный, город счастливый. Над развалившимся Днепром, весь в солнечных пятнах.

Сейчас в нем великая усталость после страшных громыхавших лет. Покой.

Но трепет новой жизни я слышу. Его отстроят, опять закипят его улицы, и станет над рекой, которую Гоголь любил, опять царственный город (Bulgakov 107).

Стоит обратить внимание на то, что, возвращаясь к истинно важному и снимая маску ироника, Булгаков точь-в-точь повторяет слова начала про- 
изведения „город прекрасный, город счастливый”. Этим он словно обозначает границы истинно важного, вневременного, отделяя его от представленной в основной части произведения картины советской суеты, теряющей всякое значение в сопоставлении с вечным.

Возвращаясь к вопросу иронии в основной части Киева-города, приведем несколько примеров и кратко представим основные приемы, использованные Булгаковым.

Итак, иронический эффект присутствует уже на уровне структуры текста и заглавий отдельных глав, их в фельетоне девять: Экскурс в область истоpuи; Status praesens; Достопримечательности; Население: Нравы и обычаи; Аскетизм; Слухи; Три ијеркви; Наука, литература и искусство; Финал.

Уже то, что десять страниц текста разделено на девять глав, вызывает комический эффект и иронически обыгрывает советскую увлеченность ясностью, краткостью, точностью и конкретностью. Впечатление упорядоченности фельетона исчезает при ознакомлении с текстом, так как практически ни одно название главы не соответствует его содержанию.

Эта особенность касается, в частности, главы с ироническим латинским названием Status praesens, из которой читатель узнает о пожаре на Крещатике, случившемся вскоре после революции, и о том, что воздушный мост в Царском саду киевляне ,до последней щепочки разнесли на дрова, а выражение «Печерска нет» - это, пожалуй, преувеличение, так как Печерск есть, но домов на большинстве улиц нету” (Bulgakov 107). Данный фрагмент показывает также иронию, вытекающую из стилистического несоответствия (сочетание латинского заглавия с появляющимся в самом начале главы разговорно-сниженным „нету”), вызывающего эффект псевдонаучности. В указанной главе, одной из самых распространенных, автор демонстративно отказывается представлять актуальную ситуацию (,status praesens”) в городе, в том числе игнорируя новые названия: вместо названия „площадь III Интернационала” пишет „бывш. Царская площадь” (ныне Европейская площадь), употребляет название „Крещатик” по отношению к главной улице Киева, свежепереименованной тогда в честь погибшего советского деятеля Вацлава Воровского (Крещатик носил имя Воровского с 1923 по 1937 год, после чего улице вернули историческое название).

Следующий пример главы с ироническим заглавием - Достопримечательности. Она целиком посвящена украинским вывескам, названным автором „ошеломляющими” (Bulgakov 102). В другой главе, правда, автор дополняет список достопримечательностей, замечая, что три действующие в Киеве православные церкви - „это еще более достопримечательно, нежели вывески" (Bulgakov 105). В данном фрагменте Булгаков использует классический пример антифраза. 
В главе Три церкви автор не углубляется в суть межконфессиональных отношений, предлагая краткое их изложение, которое религиозную ситуацию никоим образом не проясняет: „Положение таково: старая ненавидит живую и автокефальную, живая - старую и автокефальную, автокефальная - старую и живую" (Bulgakov 105).

Как ироническое следует определить также название главы Аскетизм, являющееся эвфемизмом, за которым скрывается обыкновенная послереволюционная нищета. Впрочем, в самой главе описание городской действительности сводится к констатации, что „Киев еще не вышел из периода аскетизма. В нем, например, еще запрещена оперетка" (Bulgakov 104). В данной части автор с иронией называет также характерные для Москвы признаки нэповского благополучия: „[В Киеве - А.Б.] не играют в лото на каждом перекрестке и не шляются на дутых шинах до рассвета, напившись «Абрау-Дюрсо»" (Bulgakov 104).

Очередным примером иронического заглавия является состоящая из 9 строк глава Наука, литература и искусство. Первый ее абзац звучит: „Нет”, а за ним следует краткое описание черного бюста Карла Маркса, подытоженное словами трехлетней племянницы повествователя: „Дядя Карла. Цёрный” (Bulgakov 107). Ни слова о литературе или науке в упомянутой главе нет, что наглядно свидетельствует об авторской оценке.

$\mathrm{B}$ описании памятника на будущем Майдане Незалежности появляется также пример часто встречающейся в фельетоне разновидности иронии, для раскрытия которой требуется экстралингвистическая пресуппозиция (Pohodnâ 109): „Необходимо отказаться от мысли, что изображение знаменитого германского ученого может вылепить всякий, кому не лень [выделено нами A.Б.]" (Bulgakov 107). За этим определением скрывается киевский скульптор Иосиф Моисеевич Чайков, профессор, заслуженный артист, которого Булгаков не мог не знать. Именно он в 1922 году руководил установлением перед зданием бывшей городской думы гипсовой фигуры Карла Маркса.

В контексте примера несоответствия заглавия содержанию, следует привести также упомянутый ранее Финал, который никоим образом не соотносится с основной частью текста и тем более не представляет собой ни подведения итогов, ни завершения повествования. Как насмешка над вездесущими советскими лозунгами и призывами к революционной бдительности звучат последние слова фельетона: „А память о Петлюре да сгинет” (Bulgakov 107). Иронический эффект усиливает в данном случае контраст указанной фразы с приведенными ранее лирическими рассуждениями в последнем абзаце произведения.

Отдельно следует обратить внимание на содержание главы Экскурс в область истории. Повествователь представляет в ней краткий обзор револю- 
ционных событий, используя множество метафор и иносказаний, неожиданных сравнений, дополняя все смешиванием стилей. Все это подчеркивает атмосферу полного и никому не понятного хаоса, воцарившегося после революции в Киеве:

Ни один человек в Киеве, за это я ручаюсь, не знал, что должны были обозначать эти таинственные 15 букв [за 15 буквами скрывается подпись „Депутат Бубликов” под текстом телеграммы, сообщающей об отречении Николая II - А.Б.], но знаю одно: ими история подала Киеву сигнал к началу. И началось и продолжалось в течение четырех лет. Что за это время происходило в знаменитом городе, никакому описанию не поддается. Будто уэльсовская атомистическая бомба лопнула под могилами Аскольда и Дира, и в течение 1000 дней гремело и клокотало и полыхало пламенем не только в самом Киеве, но и в его пригородах, и в дачных его местах в окружности 20 верст радиусом (Bulgakov 98).

От начала революции Булгаков сразу переходит к ее итогам, в очередной раз прибегая к иронии:

Пока что можно сказать одно: по счету киевлян у них было 18 переворотов. Некоторые из теплушечных мемуаристов [ироническое определение эмигрантских писателей - А.Б.] насчитали их 12; я точно могу сообщить, что их было 14, причем 10 из них я лично пережил.

В Киеве не было только греков. Не попали они в Киев случайно, потому что умное начальство их спешно увело из Одессы (Bulgakov 99).

Автор, сосредотачиваясь на статистической стороне вопроса и дополняя свои подсчеты упоминанием греков, не имевших никакого отношения к революционным событиям в Киеве, создает фарсовый образ истории и сознательно избегает каких-либо прямых оценок сути произошедшего.

Элементы фарса содержит также ироничное описание последнего этапа Гражданской войны в Киеве. Этот фрагмент, полный контрастов, алогизмов и антифразисов, стоит привести целиком:

На переломе второго месяца [имеется в виду конец периода, в котором Киев занимали польские войска: май-июнь 1920 г. - А.Б.] среди совершенно безоблачного неба советская конница грубо и буденно 22 заехала куда-то, куда не нужно, и паны в течение нескольких часов оставили заколдованный город. Но тут следует сделать маленькую оговорку. $\mathrm{Bce,} \mathrm{кто} \mathrm{раньше} \mathrm{делали} \mathrm{визит} \mathrm{в} \mathrm{Киев,} \mathrm{уходили} \mathrm{из} \mathrm{него} \mathrm{по-хорошему,} \mathrm{ограничиваясь} \mathrm{от-}$ носительно безвредной шестидюймовой стрельбой ${ }^{3}$ по Киеву со святошинских позиций. Наши же европеизированные кузены вздумали щегольнуть своими подрывными средствами и разбили три моста через Днепр, причем Цепной - вдребезги (Bulgakov 99).

2 Булгаков в этом месте использует игру слов: с одной стороны, украинское наречие „буденно” значит „обычно”, а с другой - отсылает к фамилии Семена Буденного, конная армия которого заняла Киев в 1920 г.

3 Автор с иронией называет „безвредной” стрельбу из 6-дюймовых гаубиц, которые в то время относились к тяжелой полевой артиллерии (см. Olejnikov, электронный ресурс). 
Глава Экскурс в область истории заканчивается нарочито оптимистичным призывом к киевлянам, в котором Булгаков с явной иронией обыгрывает стиль советских лозунгов: „Не унывайте, милые киевские граждане! Когда-нибудь поляки перестанут на нас сердиться и отстроят нам новый мост, еще лучше прежнего. И при этом на свой счет. Будьте уверены. Только терпение" (Bulgakov 100).

Булгаков в Киеве-городе ловко обходит вопрос последствий прихода большевиков к власти в Киеве, не представляя на протяжении всего текста ни одного реального достижения или полезного нововведения советского времени, ибо сложно таковыми назвать украинизацию вывесок (этому вопросу полностью посвящена упомянутая ранее глава Достопримечательноcmu) или признаки „бурной энергии” киевского коммунального хозяйства: „И сейчас уже в квартирах в Киеве горит свет, из кранов течет вода, [...] ходит по улицам этот самый коммунальный трамвай” (Bulgakov 101).

Данное высказывание следует интерпретировать иронически, так как сложно допустить мысль, что автору, выросшему в городе, ставшем в начале $\mathrm{XX}$ столетия европейской метрополией, серьезным достижением советской власти представлялось наличие электричества в киевских квартирах или „этот самый коммунальный трамвай”, который ничем, кроме названия, не отличался от дореволюционного (кстати, первого на территории Российский империи). Это обстоятельство автор явно иронически подчеркивает также в другом месте текста, употребляя слово трамвай с определением „коммунальный” без всякой надобности: „В садах большой покой. В Царском светлая тишина. Будят ее только птичьи переклики да изредка доносящиеся из города звонки киевского коммунального трамвая" (Bulgakov 101).

В данном фрагменте в очередной раз видна нерушимость вечных, вневременных начал, олицетворенных гармонией природы Царского сада (Булгаков опять игнорирует советский урбаноним - Царский сад с 1919 года носил название „сад 1-го Мая”). Его покой лишь изредка нарушают воплощающие хаос чужеродной новой действительности звонки „коммунального трамвая”.

Как было сказано выше, ирония в случае Киева-города является текстообразующим элементом и детерминирует всю идею произведения. В нем явно прослеживается напускной энтузиазм, подчеркнутый, в частности, восклицаниями типа „Не унывайте, милые киевские граждане!” или „Эх, жемчужина - Киев!” (Bulgakov 100) и диссонирующий с содержанием, из которого становится ясно, что революция обернулась для города на Днепре катастрофой и деградацией. Ирония в фельетоне Булгакова, наряду с маской наивного повествователя, скрывает горечь разочарованного человека, представителя поколения разбитых надежд. Наблюдающий постреволюционную жизнь повествователь словно старается контролировать себя и не уходить 
слишком глубоко в воспоминания о прошлом, лишь усиливающие боль утраты. Кстати, это может стать разъяснением ситуации, о которой пишет Алексей Варламов, отметивший, что „[...] в некоторых рассказах и очерках (например, Киев-город), писатель очень автобиографического склада Михаил Булгаков о своем детстве-отрочестве-юности специально ничего не написал, притом что эта тема была для русской литературы традиционной" (Varlamov, электронный ресурс). Наше предположение подтверждает резко оборванное начало произведения, в котором звучит лишенная иронии тоска по утраченному прошлому:

Но это были времена легендарные, те времена, когда в садах самого прекрасного города нашей Родины жило беспечальное, юное поколение. Тогда-то в сердцах у этого поколения родилась уверенность, что вся жизнь пройдет в белом цвете, тихо, спокойно, зори, закаты, Днепр, Крещатик, солнечные улицы летом, а зимой не холодный, не жесткий, крупный ласковый снег...

... И вышло совершенно наоборот (Bulgakov 98).

Фельетон Киев-город во многом подтверждает слова Фридриха Ницше, согласно которым ирония оказывается выражением „исторической болезни", то есть бессилия и страха современного цивилизованного человека перед будущим: „В современном человеке рядом с гордостью уживается ироническое отношение к самому себе, сознание, что ему приходится жить как бы в вечернем настроении и страхе, что он не умеет ничего сохранить для будущего из своих юношеских надежд” (цит. по: Losev, Šestakov 356).

Подытоживая наши рассуждения, следует сказать, что ироническая маска в фельетоне Киев-город становится для Булгакова стратегией освоения травматического прошлого и преодоления бессилия по отношению к чуждому настоящему. Вместе с тем автор не теряет надежды на будущее возрождение истинных ценностей и на конечный триумф вечного - эта идея, уверенно выраженная в последнем абзаце фельетона, будет повторяться как лейтмотив в более поздних произведениях Михаила Булгакова.

\section{Библиография}

Bulgakov, Mihail. Rannââ neizdannaâ proza. München, Verlag Otto Sagner in Kommission, 1976. Krivošejkina, Mariâ. Žanr fel'etona v žurnalistskom tvorčestve M.A. Bulgakova: Period raboty $v$ gazetah ,Gudok" i ,Nakanune”. Tver', Tverskij gosudarstvennyj universitet, 2004.

Losev, Aleksej, Vâčeslav Šestakov. Istoriâ èstetičeskih kategorij. Moskva, Iskusstvo, 1965.

Olejnikov, Aleksej. Tâželaâ artilleriâ Russkoj armii v Pervoj mirovoj vojne. Web. 07.12.2019. http:// www.oborona.ru/includes/periodics/armedforces/2018/0912/111125137/detail.shtml.

Petrovskij, Miron. Master i gorod: Kievskie konteksty Mihaila Bulgakova. Sankt-Peterburg, Izdatel'stvo Ivana Limbaha, 2008. 
Pohodnâ, Sofiâ. Âzykovye vidy i sredstva realizacii ironii. Kiev, Naukova dumka, 1989.

Sokolov, Boris. Bulgakov. Ėnciklopediâ. Web. 07.12.2019. http://bcoreanda.com/Downloader/ Dictionary/Bulgakov.pdf.

Trunin, Konstantin. M. Bulgakov. Kritika i analiz literaturnogo naslediâ. 2019. Web. 07.12.2019. https://reader.bookmate.com/YNE7WXte.

Varlamov, Aleksej. Žizn' zamečatel'nyh lûdej - Bulgakov. Web. 07.12.2019. http://modernlib.net/ books/varlamov_aleksey_nikolaevich/bulgakov/read.

Vvedenskij, Anton. „«Stol'nyj gorod» v drevnerusskih i fol'klornyh istočnikah”. Slověne $=$ Словгъне, 1 (3), 2014, s. 206-220. 